Journal of Social Sciences 3 (3): 159-163, 2007

ISSN 1549-3652

(C) 2007 Science Publications

\title{
Stress and Job Satisfaction among Air Force Military Pilots
}

\author{
Khodabakhsh Ahmadi and Kolivand Alireza \\ Behavioral Sciences Research Center, Baqiyatallah University of Medical Sciences, Tehran, Iran
}

\begin{abstract}
Stress induces impairment of performance is a relatively common issue in pilots of military aviation. The present study aimed at gathering preliminary data on the relationship between stress and job satisfaction among military pilots, so determine to what extent military pilots suffering from job satisfaction. This study was cross- sectional in design and used survey methodology. The survey was offered to 89 military pilots. Subjects completed a Questionnaire with 32-item on Aviation Stress and short form of Minnesota job Satisfaction Questionnaire (MSQ). Results indicated that \%33.7 pilots who had mild stress, \%48.3 pilots who exhibited moderate stress and only, $\% 13.5$ pilots who indicated high stress. The stresses in pilots rating so: life stress, organizational stress, flight environmental stress and task-based stress. The correlation between job satisfactions and life stress was (-0/53), with organizational stress $(-0 / 38)$, with flight environmental stress $(-0 / 25)$, with task-based stressors $(-0 / 23)$ and finally correlation between job satisfaction with flying hours was (-0/22). At this time when our military pilots have the least flights and spend most of their time idly, having no schedule can increase their stress, as well. Therefore, it is essential to provide them with some training, informing, evaluating and other psychological services, especially life skills and organizational skills. Furthermore, attending to military pilots and filling their schedule with useful programs such as flight with civilian airplanes, educational and research activities, favorite executive activities, sports and entertainment can decrease their stress, increase their job satisfaction and decrease their occupational weariness
\end{abstract}

Key words: Stressors, job satisfaction, air force, military pilots, performance

\section{INTRODUCTION}

The term stress originates from physical science where it refers to the force placed upon an object to cause straining, bending, or breaking. In the human context and in psychology, however, stress is often used to describe the body's responses to demands placed upon it, whether these demands are favorable or unfavorable. Anything that causes stress is called a stressor. "The military personnel are suffering from occupational stress. A majority (60\%) reported suffering from significant work stress. Almost half $(42.5 \%)$ reported that work stress was a significant contributor to the onset of their mental illness" ${ }^{\text {"[1] }}$. The aviation environment is a high risk environment and rich in potential stressors such as temperature, acceleration, noise and communication, decompression sickness, vibration, hypoxia, exhaust fumes and motion sickness. Obviously, all these environmental stressors which affecting aviation pilots both civil and military have a negative affect on the safety of flight. For example, "in military aviation the problem of motion sickness is very real and has been responsible for failure during flying training of many hopeful aircrews" ${ }^{\prime 2]}$.

The central point to all these stressors is: the effects of stressors on performance which is somehow complex

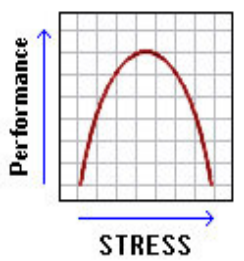

and varied. The relationship between stress and performance has been verified in many experiments and is explained by Yerkes-Dodson Law: 'PerformanceStress Relation curve'. It looks like an inverted "U". At zero arousal, that is when stress is virtually nonexistent and attention is minimal, as a consequence, the performance is zero or poor. An example of minimal stress is when someone is about to fall asleep. As stress increases, so does the level of attention, resulting in improved performance. At high level of stress, however, performance begins to deteriorate dramatically; and at maximum level of stress, that is at maximum arousal there is also zero performance- here incapacitation occurs by panic action. This is particularly true when one has to perform complex or unfamiliar tasks that require a high level of attention. The Yerkes-Dodson law has become subject of criticism as it fails to consider the effects of particular stressors encountered in aviation. "Based on a review of over 300 studies of aircrew stress, it is noted wide variations in the reported effects of particular stressors. Motivation, often considered a nuisance variable in such research, appeared to be critical and a further finding was that

Corresponding Author: $\quad$ Khodabakhsh Ahmadi, PhD, The Behavioral Sciences Research Center, Baqiyatallah Universi ty of Medical Sciences, Mollasadra Ave. Vanak Sq., P.O. Box: 19945-581, Tehran, 14548, I.R. Iran, 
background anxiety (corresponding roughly to life stress) and mission anxiety seemed more likely to impair performance than stressors such as heat",[3].

It is agreed that life stress (both positive and negative) is an important factors which may have some affects on performance. Both major life events such as death of a spouse change in residence or changing job hours and minor life stressors like a social event or a vacation have a cumulative effect that makes total stress-adaptation level, vary from person to person. Life stress may be assessed by questionnaire methods; Schedule of Recent Experiences (SRE) is one of those methods which contain a list of 42 life events. Although, "it is noted several weaknesses in the SRE, such as its failure to distinguish between positive and negative life changes and to address individual differences in the perceived desirability of a given event" ${ }^{[4]}$; but, the point is, there are special forms of life events that may be of particular relevance to military personnel that are considered among generic life events and not included in the original SRE or other general questionnaire. Events such as military disciplinary actions, permanent changes of station, involuntary assignments, operational flying mission, following orders and deference to those of higher rank are examples of life stressors in military environment.

Tension arising from a long-standing emotional conflict can induce changes in bodily function which, when repeated over a period of time, can in turn lead to actual tissue damage. The association between stressful life events (both positive and negative) and heart disease and other illnesses is well known. For many years attempts have been made to delineate particular incidence of life events associated with involvement of flying accident, however, review of these literatures fails to reveal a specific statistical relation. Although," individual case studies tend to support such a notion, but statistical population studies do not provide any corroboration $"$ "2].

Pilot Performa are a variety of complex tasks requiring a high degree of both physical and mental well being. "The complexity of the tasks, itself, is associated with workload which represents task-based stressors" $[3]$. There are certain times during a flight when workload tends to peak. High workload tends to occur during the takeoff and final approach phases of flight. During these times, any additional work, such as an ATC request for a change in flight plan, is very difficult to handle and may reduce the performance of operator. The workload can compromise aviator performance by producing critical level of fatigue. "The key scheduling factors contributing to the development of aircrew fatigue are multiple night flight, multiple time-zone displacement, flights departing 24 hours after an evening arrival and multiple takes off and landing. Additional aggravating factors include departure delay of several hours that require pilots to lounge about airports, in-flight malfunctions, emergencies, adverse weather, or other factors that markedly increase workload" $"$ [5].
Job satisfaction is the degree to which people like their jobs. Some people enjoy work and find it to be a central part of life. Others hate to work and do so only because they must. The study of the causes and consequences of these important issues is one of the major domains of organizational psychology. Job satisfaction is directly related to job performance, attitude, motivation and morale. "Job dissatisfaction was predicted by lack of career opportunities, poor organizational climate and morale and lack of autonomy at work, together with some domestic stressors (e.g., family health)",[6]. It is shown that many factors related to job satisfaction such as: "higher motivation and ego strengths of fliers" ${ }^{[8]}$, "personality characteristics"[7], "self-perceived fatigue and career opportunities" $^{\prime[6]}$. These factors can increase the ability to cope with stressful conditions.

Job satisfaction may be assessed by questionnaire method and Minnesota Job Satisfaction (MSQ) is one of those methods. Job satisfaction is determined by a great many factors and it would be extremely difficult to control for all of the individual differences that exist and may affect job satisfaction; therefore, when assessing a criterion such as job satisfaction, it should be remembered that there could be any number of other variables besides those which are measured by simple questionnaires and need to consider that they are influencing the results. The present study aimed at gathering preliminary data on the relationship between stress and job satisfaction among military pilots. The primary goal of this study is to explore the stressors that affect pilots in their field of practice and to determine to what extent military pilots suffering from job satisfaction.

\section{MATERIALS AND METHODS}

This study was cross- sectional in design and used survey methodology. The survey was offered to 89 military pilots. All participants were male with mean age of 35 years and the average total flying hours of respondents was 1441 hours. Participants completed a 32-item survey developed by investigators that included items on four groups of stressors witch already mentioned i.e.: life stress, organizational stress, taskbased stress and flight environment stress. Scales developed from these factors showed acceptable internal consistency and reliability. The participants also completed the short form of Minnesota job Satisfaction Questionnaire (MSQ). The Minnesota Satisfaction Questionnaire (MSQ) is designed to measure an employee's satisfaction with their particular job. The MSQ is a 100-item, self-report instrument. It measures job satisfaction across 20 different dimensions, with five questions on each dimension. The short-form MSQ consists of 20 items from the longform MSQ that best represent each of the 20 scales. The data were analyzed using the SPSS software and for all analyses, statistical significance was set at $\mathrm{P}<0.01$ or $\mathrm{P}<0.05$. 


\section{J. Social Sci., 3 (3): 159-163, 2007}

\section{RESULTS AND DISCUSSION}

In terms of prevalence of stress among the military pilots the following results obtained (Table 1). There were 4 pilots $(\% 4.5)$ reported very low level of stress, 30 pilots (\%33.7) who had mild stress, 43 pilots (\%48.3) who exhibited moderate stress and only, 12 pilots (\%13.5) who indicated high stress. Significantly, there were no pilots reported of very high or sever stress at all.

\begin{tabular}{lcc} 
Table1: & Prevalence of stress & \\
\hline Stress & Frequency & Percent \\
\hline Very Low Stress & 4 & $\% 4.5$ \\
Low Stress (Mild) & 30 & $\% 33.7$ \\
Moderate Stress & 43 & $\% 48.3$ \\
High Stress & 12 & $\% 13.5$ \\
Very High Stress & 0 & 0 \\
Total & 89 & $\% 100$ \\
\hline
\end{tabular}

Of the four groups of stressors, the life stress had maximum rate of incidence (with average of 6/45 $2 / 3$ ), the organizational stressors with average rate of $(5.05 \pm$ $2 / 1$ ), the flight environmental stress with average of $(4 / 03 \pm 1 / 9)$ and finally, the task-based stressors had minimum rate of incidence (average 3/91 $\pm 2 / 1$ ).

In comparison the difference between four groups of stresses among military pilots, it is revealed that there were significant differences among the four groups $(p \leq 0 / 01)$. However, there was no difference between flight environmental stress and task-based stress (Table 2).

In term of correlation between the variables of tests by using "P correlation coefficient", it showed that correlation between job satisfactions and life stress was $(-0 / 53)$, with organizational stress $(-0 / 38)$, with flight environmental stress $(-0 / 25)$, with task-based stressors $(-0 / 23)$ and finally correlation between job satisfaction with flying hours was $(-0 / 22)$. Note that all variables had inverse correlation and the differences were $(\mathrm{p} \leq 0 / 01)$.

Nevertheless, in respect of correlation coefficient between different groups of stresses among military pilots, it was shown the correlation coefficient between flight environmental stress and task-based stress was 0/84, between flight environmental stress and organizational stress was $0 / 79$, between life stress and organizational stress was $0 / 69$, between task-based stress and organizational stress was $0 / 69$, between life stress and flight environmental stress was 0/49 and finally the correlation coefficient between life stress and flight environmental stress was $0 / 46$. There was also correlation $(-0 / 22)$ between pilots' flight hours and job satisfaction (Table 3).
Since flying especially military flying is a sensitive job and any possible error incurs harmful consequences for human, economy and security, it is essential for aviation organizations to study and try the ways to reduce pilots' errors. Stress is an insidious threat to aviation safety because of the impairments in alertness and performance it creates. Different studies have shown the rate of mental disorders in air force pilots and those involved in bombardment and air raid are much more than that in civilian pilots. Furthermore, psychological diseases are the second reason for losing flight license (after cardiac diseases) ${ }^{[3,10]}$. Since it is possible that some pilots continue their flights despite their psychological disorders that is why evaluating the level of pilots' stress and mental heaths, recognizing sources of stress and reducing them is an important duty of aviation organizations.

The previous studies were shown:" the wide range of reported job satisfaction and stress among Air Force military training instructors" ${ }^{[7]}$ and the present study also revealed $13.5 \%$ of military pilots have high stress and $48.3 \%$ have average stress. Among the four stress sources witch were studied in military pilots in this research, life stress and organizational stress have the highest rate $(\mathrm{m}=6.45 \& 5.05)$ respectively. In contrast to the common belief that life stress and organizational stress should be considered minor sources of stress, they have the highest scores in our research. This difference can be attributed to efforts made to improve professional skills of military pilots while no attempt is made to teach them social and family life skills, compatibility and adjustment skills; and this study clearly emphasized the role of psychological consultative and psychiatric services in a pilot's curriculum. "Using findings from the other scientific studies, the family member can be a major social support system for the aviator and a significant factor in the pilot's ability to deal effectively with psychosocial stress" [11].

Another finding in this study was the correlation between rate of stress and job satisfaction and flight experience (flight hours). It is noticed from this research that the correlation between job satisfaction and stress in military pilots were between -0.23 to 0.53 . That for job satisfaction and life stress was -0.53 , for organizational stress and job satisfaction was -0.38 , for flight environment stress and job satisfaction was 0.25 and for task based stress and job satisfaction was 0.23 . These figures show that life stresses enter military pilots' work place, which signifies the mixture of professional life with family life. Life stresses such as relation with wife, communication with children, familial interaction, financial management, family and friends and marital conflicts both impose the highest stress on the studied group of pilots and have the 
J. Social Sci., 3 (3): 159-163, 2007

Table 2: Comparison among different groups of stresses using $t$ value

\begin{tabular}{|c|c|c|c|c|}
\hline Group & Mean & SD & $\mathrm{t}$ Value & $\mathrm{P}$ \\
\hline Life Stress & $6 / 45$ & $2 / 3$ & $10 / 66$ & $<0 / 0001$ \\
\hline \& Flight Environment Stress & $4 / 03$ & $1 / 9$ & & \\
\hline Life Stress & $2 / 3$ & $2 / 3$ & $10 / 46$ & $<0 / 0001$ \\
\hline \& Task-Based Stress & $3 / 91$ & $2 / 1$ & & \\
\hline Life Stress & $6 / 45$ & $2 / 3$ & $7 / 64$ & $<0 / 0001$ \\
\hline \& Organizational Stress & $5 / 05$ & $2 / 1$ & & \\
\hline Flight Environment Stress & $4 / 03$ & $1 / 9$ & $0 / 95$ & $0 / 34$ \\
\hline$\&$ Task-Based Stress & $3 / 91$ & $2 / 1$ & & \\
\hline Flight Environment Stress & $4 / 03$ & $1 / 9$ & $-7 / 35$ & $<0 / 0001$ \\
\hline \& Organizational Stress & $5 / 05$ & $2 / 1$ & & \\
\hline Task-Based Stress & $3 / 91$ & $2 / 1$ & $-6 / 49$ & $<0 / 0001$ \\
\hline \& Organizational Stress & $5 / 05$ & $2 / 1$ & & \\
\hline
\end{tabular}

Table 3: Correlation coefficient between job satisfaction, stresses and flight hours

\begin{tabular}{|c|c|c|c|c|c|c|}
\hline Flying hours & $\begin{array}{l}-0 / 22 \\
\mathrm{p}=0 / 02\end{array}$ & & & & & \\
\hline General Stress & $\begin{array}{l}-0 / 38 \\
\mathrm{p} \leq 0 / 0001\end{array}$ & $\begin{array}{l}-0 / 04 \\
\mathrm{p}=0 / 35\end{array}$ & & & & \\
\hline Life Stress & $\begin{array}{l}-0 / 53 \\
\mathrm{p} \leq 0 / 001\end{array}$ & $\begin{array}{l}-0 / 13 \\
\mathrm{p}=0 / 12\end{array}$ & $\begin{array}{l}0 / 72 \\
p=0 / 0001\end{array}$ & & & \\
\hline Flight Environmental Stress & $\begin{array}{l}-0 / 25 \\
\mathrm{p}=0 / 009\end{array}$ & $\begin{array}{l}0 / 002 \\
p=0 / 49\end{array}$ & $\begin{array}{l}0 / 92 \\
p=0 / 0001\end{array}$ & $\begin{array}{l}0 / 49 \\
\mathrm{p}=0 / 0001\end{array}$ & & \\
\hline Task-based Stress & $\begin{array}{l}-0 / 23 \\
\mathrm{p}=0 / 01\end{array}$ & $\begin{array}{l}-0 / 006 \\
\mathrm{p}=0 / 48\end{array}$ & $\begin{array}{l}0 / 89 \\
p=0 / 0001\end{array}$ & $\begin{array}{l}0 / 46 \\
\mathrm{p}=0 / 0001\end{array}$ & $\begin{array}{l}0 / 84 \\
p=0 / 0001\end{array}$ & \\
\hline Organizational Stress & $\begin{array}{l}-0 / 38 \\
\mathrm{p}=0 / 0001\end{array}$ & $\begin{array}{l}-0 / 04 \\
\mathrm{p}=0 / 37\end{array}$ & $\begin{array}{l}0 / 91 \\
p=0 / 0001\end{array}$ & $\begin{array}{l}0 / 69 \\
\mathrm{p}=0 / 0001\end{array}$ & $\begin{array}{l}0 / 79 \\
p=0 / 0001\end{array}$ & $\begin{array}{l}0 / 69 \\
p=0 / 0001\end{array}$ \\
\hline Groups Of Stress & Job Satisfaction & Flying Hours & General Stress & Life Stress & Flight Environmental Stress & Task-based Stres \\
\hline
\end{tabular}

highest impact on their job satisfaction. Having simultaneous high stress and low job satisfaction indicates occupational weariness and burnout ${ }^{[12]}$, which is defined as the physical and mental tiredness and decrease in capabilities due to occupational stress. Even unresolved occupational stress can lead to occupational weariness and the occupational weariness and burnout, lead one's to change of him/his job ${ }^{[13]}$.

At this time when our military pilots have the least flight activity and spend most of their time at their organization idly and having no effective schedules can increase their stress. Therefore, it is essential to provide them with some training, informing, evaluating and other psychological services, especially life and organizational skills. Furthermore, filling their schedule with useful programs such as flight with civilian airlines, educational and research activities, favorite executive activities, sports and entertainment can decrease their stress, increase their job satisfaction and decrease their occupational weariness.

\section{REFERENCES}

1. Pflanz, S., 2001. Occupational stress and psychiatric illness in the military: investigation of the relationship between occupational stress and mental illness among military mental health patients. Mil. Med., 166: 457-62

2. Harding, M. Richard Mills and F. John, 1988. Aviation Medicine. 2nd Edn. BMJ Press, U.K.P., 96: 113.

3. Farmer, E.W. and H.M. Mclntyre, 2000. Crew Resource Management. In Ernsting, J. Nicholson, A.n. and Rainford, D.J. Aviation Medicine. 3rd Edn. London Butterworth-Heinemann, pp: 609-610.

4. Farmer, E.W., 1955. Stress and Workload. In Ernsting, J., King, P. Aviation Medicine. 2nd Edn. London Butterworth-Heinemann, pp: 435.

5. Sheriden, T.B. and R.Y. Laurence, 1996. Human Factors in Aerospace Medicine. In Dehart, Roy. L. Fundamentals of Aerospace Medicine. 2nd Edn. Baltimor Williams and Wilkins Copy, U.S.A., pp: 899. 
6. Cooper, C.L. and S. Sloan, 1985. Occupational and psychosocial stress among commercial aviation pilots. J. Occup. Med., 27: 570-6.

7. Carbone, E.G. and J.A. Cigrang, 2001. Job satisfaction, occupational stress and personality characteristics of Air Force military training instructors. Mil. Med., 166: 800-2.

8. Cetinguc, M., 1992. An assessment of Turkish Air Force pilots' anxiety and depression levels. Aviat. Space Environ. Med., 63: 905-7.

9. Parker, J.F.Jr., 1996. Management of Human Resource in Air Transport Operations. In Dehart, Roy, Fundamentals of Aerospace Medicine. 2nd Edn. Baltimore Williams and Wilkins Copy, U.S.A., pp: 933.
10. Holleran, R.S., 1996. Flight Nursing Principles and Practice. 2nd Edn, St. Louis.U.S.A. Mosby Press, pp: 692.

11. Karlins, M., F. Koh and L. McCully, 1989. The spousal factor in pilot stress. Aviat. Space Environ. Med., 60: 1112-5.

12. Farber, B.A., 1983. Stress and burnout in the human service professions. New York: I. T. P.

13. Williams . B.K. and S.M. Knight, 1994. Health for Living Wellness and the Art of Living. Pacific Grove: Brooks/cole. 